\title{
ProBNP for Stratifying Patients with Heart Failure
}

\author{
A ntonio Carlos Pereira-Barretto, Mucio Tavares de O liveira Jr, Fabio Gazellato Franco, \\ Célia Cassaro-Strunz \\ São Paulo, SP - Brazil
}

\begin{abstract}
Objective - To verify whether the serum levels of $N$ Terminal ProBNP fraction (ProBNP) allow us to identify with accuracy the clinical functional status of patients with heart failure (HF), because the clinical diagnosis of this syndrome is based basically on clinical data when the complementary tests have lower specificity.
\end{abstract}

Methods - Sixty-nine patients with a history of HF were studied. Their mean age of was 53.5 years and $78.3 \%$ were males. All underwent clinical and echocardiographic evaluations and a test to determine the serum dosage of ProBNP. According to clinical manifestation, patients were in the following functional classes $(F C), 14 \%$ FC I, $40.6 \%$ FC II, $28.1 \%$ FC III, and $23.4 \%$ FC IV. The mean ejection fraction (EF) was 0.28 .

Results - ProBNP did not differ according to age, sex, and cause of cardiopathy. No correlation existed between EF and the ProBNP serum level. ProBNP levels were significantly lower in patients in FC I than those in FC II (42 vs $326.7 \mathrm{pmol} / \mathrm{L} ; \mathrm{P}=0.0001$ ), and in FC II than those in FC III $(P=0.01)$. ProBNP levels did not differ statically between $F C$ III and IV patients (888.1 vs $1082.8 \mathrm{pmol} / \mathrm{L} ; P=0.25)$. ProBNP values greater than $100 \mathrm{pmol} / \mathrm{L}$ identify patients with decompensated $H F$ with a sensitivity of $98 \%$.

Conclusion - ProBNP values over $100 \mathrm{pmol} / \mathrm{L}$ were indicative of $H F$, and patients with advanced HF had values over $270 \mathrm{pmol} / L$. A ProBNP dosage test was an excellent auxiliary in the clinical characterization of patients with $\mathrm{HF}$.

Keywords: heart Failure, ProBNP, decompensation

Instituto do Coração do Hospital das Clínicas - FMUSP

Mailing address: Antonio Carlos Pereira-Barretto - InCor-Av. Dr. Enéas C. Aguiar, 44 - 05403-000 - São Paulo, SP - Brazil - E-mail: pereira.barretto@incor.usp.br Received - 1/28/03

Accepted - 4/14/03
Heart failure (HF) is a syndrome that is diagnosed based fundamentally on clinical data ${ }^{1-5}$. Based on the patients' symptoms, a clinical hypothesis is made and the clinical signs help confirm the hypothesis, but often, especially in the mild forms, clinical signs do not help in define the illness. The complementary tests when positive help with the diagnosis, but frequently it is difficult to define a positive result. For example, a normal left ventricular ejection fraction does not allow the ruling out of HF (HF could be due to diastolic dysfunction). And if the ejection fraction is reduced, this does not indicate unequivocally that the patient has HF, because the patient could have asymptomatic left ventricular systolic dysfunction.

In addition, test results are usually unspecific.

Until recently, no laboratory test was available that was a real marker of cardiac decompensation. Natriuretic peptide levels are precociously elevated in HF, they are liberated by atrial and ventricular distention, and they mark the presence of cardiac failure ${ }^{6-10}$. Many studies have shown a good correlation between the extent of elevation of natriuretic peptides and the presence of $\mathrm{HF}^{6-10}$.

In this article, we present our initial experience with ProBNP dosage in the diagnosis and therapeutic treatment of patients with $\mathrm{HF}$.

\section{Methods}

Sixty-nine patients with a history of HF were studied, 45 with chronic HF from the outpatient unit and 24 with decompensated HF from the emergency unit or hospitalized for compensation. The patients' ages ranged from 18 to 84 years (mean $53.5 \pm 12.9$ years); 54 were males and 15 were females.

After clinical evaluation, the patients were classified according to New York Heart Association functional classes (FC) as follows: 9 in FC I, 27 in FC II, 18 in FC III, and 15 in FC IV. Based on clinical history and laboratory tests, we identified the following causes of the cardiopathies: 24 related to hypertension, 16 due to coronary heart disease, 15 
due to Chagas disease, 12 due to idiopathic dilated cardiomyopathy, and 2 due to a valvar disease.

All patients underwent an echocardiographic study, and we selected for this study left ventricular end-diastolic diameter and left ventricular ejection fraction.

The echocardiographic data showed a left ventricular end-diastolic diameter that ranged from 45 to $94 \mathrm{~mm}$ (mean $68.9 \pm 10.6 \mathrm{~mm}$ ) and an ejection fraction from 0.12 to 0.66 (mean $0.28 \pm 0.10$ ).

The ProBNP dosage was obtained by using the Roche kit (Mannheim, Germany) in automated Elecsys 1010 equipment (Roche Diagnostica, Brasil). All the dosages were processed on the same day to avoid the inter-day variations. The intra-day coefficient of the method is $\leq 3.0 \%$.

Hospitalized patients had their clinical situation reevaluated after 10 days, and they were divided into 2 groups, those who were discharged and those who remained in the hospital.

For the numeric variables, we calculated the arithmetic median and its standard deviation and the comparison between them were made with the Student $t$ test. Significance were considered $\mathrm{P}<0.05$ for the bicaudal tests.

\section{Results}

ProBNP values ranged from 10.4 to $4139 \mathrm{pmol} / \mathrm{L}$ (mean $590.4 \pm 772.4 \mathrm{pmol} / \mathrm{L}$ ).

No correlation existed between ProBNP level and age, sex, cause of cardiopathy, left ventricular ejection fraction, and end-diastolic diameter.

Table I depicts the clinical and echocardiographic data and the ProBNP level according to FC. Left ventricular enddiastolic diameter was smaller in patients in FC I than in those in FC II and III and was similar to those in FC IV. Patients in FC II had greater left ventricular end-diastolic diameters. No difference existed between the left ventricular end-diastolic diameter of patients in FC III and IV.

The ProBNP values were different according to FC (tab. I). The values for FC I patients $(42 \pm 34.4 \mathrm{pmol} / \mathrm{L})$ were different from those in all the others $\mathrm{FC}$ patients $(\mathrm{P}=0.0001)$. Patients in FC II $(326.7 \pm 326.51 \mathrm{pmol} / \mathrm{L})$ had lower values than did patients in FC III and IV ( $\mathrm{P}=0.01)$. Patients in FC III $(888.1 \pm 892.1 \mathrm{pmol} / \mathrm{L})$ had values similar to those of patients in FCIV $(1082 \pm 1045.1 \mathrm{pmol} / \mathrm{L}(\mathrm{P}=0.25)$ (fig. 1$)$. The other studied variables were similar.

Analyzing our results, we noticed that if we consider the value of $100 \mathrm{pmol} / \mathrm{L}$ as the limit for compensated and decompensated HF, only 1 patient in FC I had a dosage greater than $100 \mathrm{pmol} / \mathrm{L}(120 \mathrm{pmol} / \mathrm{L})$, and only 5 patients with symptomatic $\mathrm{HF}$ had values under $100 \mathrm{pmol} / \mathrm{L}$ (all in FC II). No patient in FC II or IV had values of ProBNP lower than $270 \mathrm{pmol} / \mathrm{L}$.

Patients from the emergency unit and those hospitalized for compensation had ProBNP values of $921.3 \pm$ $1128.5 \mathrm{pmol} / \mathrm{L}$. Patients who were released before 10 days of follow-up had mean ProBNP values of $619.2 \pm 414.8 \mathrm{pmol} / \mathrm{L}$, and those who remained in the hospital after 10 days of treatment had mean ProBNP values of $1616.6 \pm 1568.1 \mathrm{pmol} /$ $\mathrm{L}(\mathrm{P}=0.096)$.

\section{Discussion}

ProBNP dosage analysis fills a gap in the diagnostic area, making it possible to diagnose HF through a laboratory test with great sensitivity and specificity ${ }^{6-11}$.

$\mathrm{HF}$ is a disease that in recent years has been increasingly studied, because it has become more frequent and it is responsible for growing public health and also private income expenses. HF is a progressive syndrome with a poor prognosis for those with the advanced form ${ }^{12-14}$.

Early identification of left ventricular systolic dysfunction, even in HF patients, allows us to begin treatment with ACE inhibitors and beta-blockers earlier, modifying the natural history of the disease ${ }^{15,16}$.

One problem with HF is its correct identification, usually empiric and based primarily on clinical manifestations that many times are nonspecific ${ }^{1-5}$. The complementary tests, usually of great help in identifying HF, are also of lower specificity, the result being that many patients are wrongly diagnosed. This difficulty is even greater in the aged patients, once co-morbidities have become more frequent.

Fatigue, dyspnea, and leg edema are the most frequent symptoms that allow us to diagnose HF, but they are also symptoms related to pulmonary, hepatic, or renal diseases, making the differential diagnosis difficult and uncertain, and also not allowing us to rule out the concomitance of these diseases.

\begin{tabular}{|c|c|c|c|c|}
\hline \multirow[t]{2}{*}{ Variable } & \multicolumn{4}{|c|}{ Functional class } \\
\hline & FCI & FC II & FC III & FCIV \\
\hline $\mathrm{N}$ & 9 & 27 & 18 & 15 \\
\hline Age (years) & 56.7 (11.6) & $49.7(9.3)$ & $54.7(11.7)$ & $57.5(19.2)$ \\
\hline Male (\%) & $77.7 \%$ & $86.3 \%$ & $77.7 \%$ & $60 \%$ \\
\hline LVEF & $0.32(0.12)$ & $0.27(0.06)$ & $0.26(0.08)$ & $0.29(0.14)$ \\
\hline LVEDD (mm) & $60.3(5.8)$ & $74.6(7.9)$ & $68.3(11.5)$ & $63.6(11.5)$ \\
\hline ProBNP (pmol/L) & $42(34.4)$ & 326.7 (326.5) & $881.1(892.1)$ & $1082.7(1045.1)$ \\
\hline
\end{tabular}




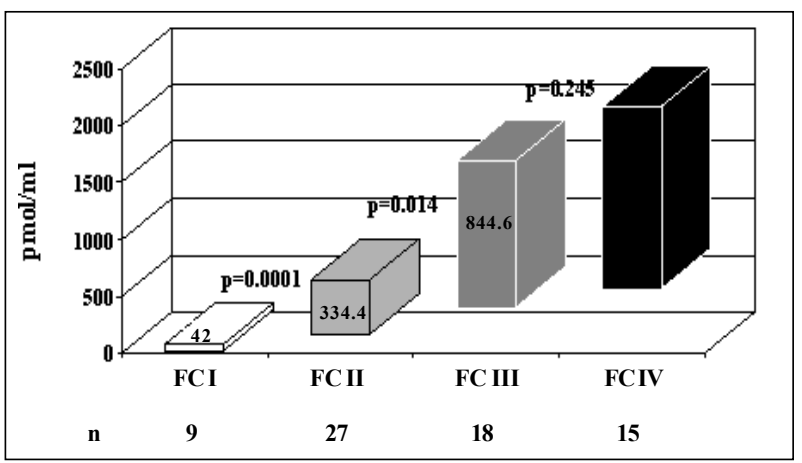

Fig. 1 - Graphic showing the mean values and standard deviation values from ProBNP according to functional classes.

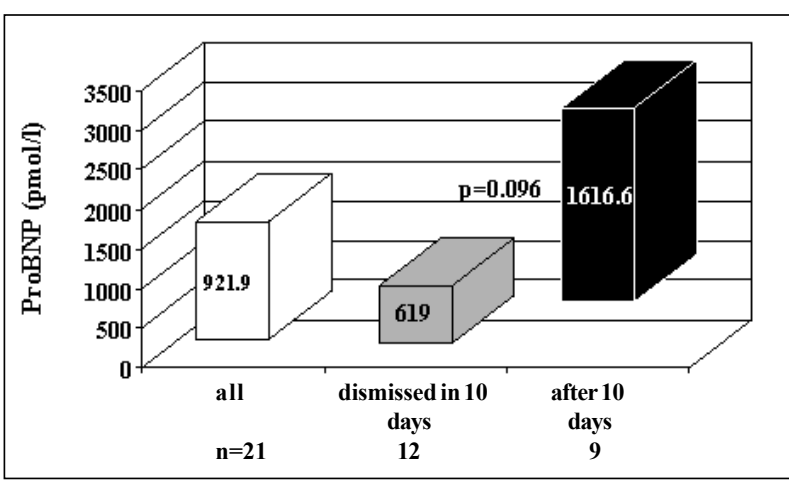

Fig. 2 - Graphic showing the proBNP mean values of hospitalized patients who could or could not be discharged after 10 days of treatment.

Jugular ingurgitation and the third heart sound are more specific clinical signs that help us in the characterization of this syndrome, but they are not present in the early forms and they can be intermittent ${ }^{1-5}$. Of the complementary tests, not one allows us to systematically diagnose HF.

Clinical diagnosis based on evidence has been of low efficacy and probably was responsible for the poor results obtained in many clinical trials. The digitalis studies are one good example of these poor results. When the patient selection was based on symptoms, the digitalis studies showed that the patients taking or not taking digitalis had a similar outcome ${ }^{17-19}$, the exception being those with a third heart sound, when digitalis suspension provokes clinical deterioration ${ }^{17}$. On the other hand, when patient selection was based on left ventricular systolic dysfunction (ejection fraction lower than 0.40 ), it was possible to verify that digitalis improves clinical symptoms and outcome and that suspension of digitalis induces a clinical deterioration in the majority of the patients ${ }^{20-22}$.

Besides this difficulty in diagnosing HF based on clinical symptoms and signs, in patients with HF, stratification according to symptom intensity (New York Heart Association) is of great utility in identifying which patient might have a worse outcome. But in specific groups, such as in patients with the advanced form of the disease in FC III/IV, the FC classification looses its capacity to identify which patients will have a worse prognosis, and additional parameters are necessary for this stratification ${ }^{23-27}$.
Echocardiography is without a doubt a great help in diagnosing HF because it provides much information related to the disease. Echocardiography allow us to evaluate cardiac remodeling, to identify and quantitate valvar dysfunction, to evaluate whether left ventricular contraction is homogeneous or whether it has segmentary compromise, all important information for the correct diagnosis of $\mathrm{HF}$ and its cause. However, none of these data are specific, because they could be present but the patient may not have HF. Our observation showed that left ventricular ejection fraction and the magnitude of left ventricular dilatation may be similar in patients with or without HF and in patients with the advanced form of the disease ${ }^{22-25}$. Results from the SOLVD studies on prevention and treatment ${ }^{26,27}$ also demonstrate that left ventricular ejection fraction per se does not aid in the diagnosis of HF, because in the 2 studies a reduced ejection fraction (lower than 0.35 ) was the inclusion criterion, and the only difference observed was the presence of symptoms in the treatment arm of the study.

Left ventricular systolic dysfunction is the leading cause of HF and one important prognostic determinant of this syndrome, but the peripheral vascular situation of each patient is of great importance in cardiac decompensation. However, it was difficult to evaluate and it can be altered by systemic diseases. So, when we evaluate only cardiac function, it may not represent the patient's clinical situation ${ }^{22-28}$.

Experience with natriuretic peptide dosages is growing and may show that it may reduce this deficiency, once the studies have shown that it has a great specificity for identifying which patients have $\mathrm{HF}^{6-10}$. At present, 4 natriuretic peptides have been described, all structurally similar, but genetically distinct, identified by the first 4 letters of the alphabet. Atrial natriuretic peptide (ANP) is secreted primordially by the atrium in response to atrial distension. BNP is secreted by the atrium and by ventricular myocardium cells. CNP is expressed in the central nervous system and endothelium. The appropriate DNP locale of formation is not known, with some controversy about whether it is a real neurohormone or a degradation product of the other peptides ${ }^{6}$.

Many studies have shown that A, B, and D peptide levels are elevated in HF. CNP is not elevated in $\mathrm{HF}^{6}$.

Cardiac fiber distention due to cardiac chamber volume or pressure overload and other neurohormonal activation (endothelin-1) triggers peptide natriuretic stimulation. BNP level has a direct correlation with functional class and with hemodynamic measures including left ventricular diastolic pressure and is the inverse of left ventricular ejection fraction ${ }^{6-11}$. These studies had shown that elevated BNP levels are indicative of the greater morbidity and mortality observed in this syndrome ${ }^{6-11}$.

A great number of studies ${ }^{6-11}$ on natriuretic peptide dosages are showing that elevated levels could be of help in identifying patients with $\mathrm{HF}$, in detecting left ventricular diastolic dysfunction, and in making the differential diagnosis of dyspnea. Based in these results, the guidelines for $\mathrm{HF}$ treatment include BNP dosage as a guiding element in the algorithm of HF diagnosis along side of electrocardiography and thoracic X-rays ${ }^{4,5}$. 
$\mathrm{BNP}$ is a vasodilator neurohormone with natriuretic, diuretic, and antimutagen effects. BNP levels increase precociously in patients with left ventricular dysfunction, as demonstrated in large trials. In the SAVE and SOLD prevention trials, it was possible to observe that in patients with asymptomatic left ventricular systolic dysfunction, among the elevated neurohormones a significant and precocious elevation existed in natriuretic peptides ${ }^{26,29}$. Vasodilatation promoted by this elevation could be the explanation for the good hemodynamic situation, a fact that could result in the absence of symptoms observed in these patients. When we analyzed which neurohormones were elevated, we observed that natriuretic peptide was the one that had the greatest elevation ${ }^{26,29}$. So, the dosage of these natriuretic peptides allows us to diagnosis left ventricular dysfunction even when patients remain asymptomatic.

B-type natriuretic peptide levels can be determined by 2 methods: through the analysis of BNP or through the dosage of N-terminal fraction of BNP, that is a biological inactive degradation product of ProBNP. The results of these 2 analyses were very similar $\left(r^{2}=0.94\right)$, the ProBNP levels being more elevated than those of BNP $(3.48 \text { times })^{30}$. A possible advantage of ProBNP analysis over BNP analysis is related to the greater stability in vitro (until 3 days at ambient temperatures), that could be of importance when transportation is considered and also related to greater plasmatic concentration that results in fewer mistakes in analysis.

Our results are similar to those reported in the literature ${ }^{30-34}$, where patients with $\mathrm{HF}$ had more elevated levels of ProBNP than those in FC I. In those studies in which ProBNP was used to diagnose $\mathrm{HF}^{31-34}$, values over 120 and $140 \mathrm{pmol} / \mathrm{L}$ were found to be an indicator of the presence of HF. Our results were very similar, because no single patient in FC I had values of ProBNP greater than $120 \mathrm{pmol} / \mathrm{L}$. Data in the literature regarding FC II patients suggest values around $250 \mathrm{pmol} / \mathrm{L}$ and for patients with more severe forms values around $450 \mathrm{pmol} / \mathrm{L}$. In our data, we observe for FC II patients a mean value of $320 \mathrm{pmol} / \mathrm{L}$.

ProBNP results allow us to stratify with greater precision the group of HF patients, because we find very high values in patients with severe symptoms (FC III/IV), intermediate values for those in FC II, and in patients with asymp- tomatic left ventricular dysfunction values under $120 \mathrm{pmol} /$ L (fig. 1). ProBNP dosage efficiently identifies symptomatic patients, and in this group of patients this identification was more sensible than that obtained through echocardiography, because the majority had left ventricular ejection fraction around 0.35 (tab. I).

Besides its utility for diagnosing and stratifying patients with HF, ProBNP levels measured on the beginning of the hospitalization allow us to identify which patient will need more than 10 days to compensate. Hospitalized patients with greater levels of ProBNP had more difficulty in compensating than did those with lower levels (fig. 2).

In relation to data in the literature, we observed that our results in FC III/IV patients were more elevated, which is to be expected, because our study population had more severe cardiac compromise than did those usually described in most of the published reports. We emphasize this because the 1-year mortality observed in our patients was approximately $60 \%$, while that reported in the literature was under $40 \%{ }^{23-25,35,36}$.

Beside its value for diagnosing $\mathrm{HF}$ and left ventricular asymptomatic dysfunction, ProBNP or BNP dosage may be of utility for orienting patient treatment, because with efficacious treatment the natriuretic peptide levels will be reduced ${ }^{31}$. If the reduction does not occur, it signals that the treatment is not efficacious or that the patient has a severe form of the disease with a very poor prognosis ${ }^{31,32}$. The literature shows that guided treatment through natriuretic peptide levels induces more expressive results than those based on subjective clinical evaluation by the clinician ${ }^{31}$.

This initial experience with ProBNP dosage shows us its clinical utility for diagnosing HF. No patient without symptoms has values over $120 \mathrm{pmol} / \mathrm{L}$, and the majority have values under $100 \mathrm{pmol} / \mathrm{L}$. Symptomatic patients had elevated levels with a $98 \%$ sensitivity, and the more symptomatic patients had greater values. ProBNP levels have a better correlation with $\mathrm{FC}$ than with echocardiographic data, once left ventricular end-diastolic diameter and ejection fraction were similar in the differentFC patients, but the ProBNP levels were significantly different. ProBNP dosage helps identify which patient can be discharged with limited hospital care and points us toward those who will need more attention.

\section{References}

1. Braunwald E, Collucci WS, Grossman W. Clinical aspects of heart failure. In: Braunwald E., ed. Heart Disease. A Textbook of Cardiovascular Medicine. 5th Edition. Philadelphia: WB Saunders Co., 1997: 445-70.

2. Stocco R, Pereira-Barretto AC. Insuficiência Cardíaca Congestiva - Critérios Diagnósticos. In: Timerman A, Cesar LAM, eds. Manual de CardiologiaSOCESP. 1st Edition. São Paulo: Atheneu, 2000: 32-5.

3. Drazner MH, Rame JE, Stevenson LW, Dries DL. Prognostic importance of elevated jugular venous pressure and a third sound in patients with heart failure. $\mathrm{N}$ Engl J Med 2001; 345: 574-81.

4. Remme WJ, Swedberg K. Task force report. Guidelines for the diagnosis and treatment of chronic heart failure. Eur Heart J 2001; 22: 1527-60.

5. II Diretrizes para o Diagnóstico e Tratamento da Insuficiência Cardíaca. Arq Bras Cardiol 2002; 79(suppl IV): 1-46.
6. Adams KF, Mathur VS, Georghiade M. B-type natriuretic peptide: from bench to bedside. Am Heart J 2003; 145: S34-S46.

7. Masel AS, KrishnaswamY P, Nowak RM, et al. Rapid measurement of B-type natriuretic peptide in the emergency diagnosis of heart failure. N Engl J Med 2002; 347: 161-7.

8. Koglin J, Pehlivanli S, Schwaiblmair M, et al. Role of brain natriuretic peptide in risk stratification of patients with congestive heart failure. J Am Coll Cardiol 2001; 38: 1934-41.

9. Villacorta H, Duarte A, Duarte NM, et al. Valor do peptídeo natriurético cerebral no diagnóstico de insuficiência cardíaca congestiva em pacientes atendidos com dispnéia na unidade de emergência. Arq Bras Cardiol 2002; 79: $564-$ 72

10. Morrison LK, Harrison A, Krishnaswamy P, et al. Utility of a rapid B-natriuretic 
peptide assay in differentiating congestive heart failure from lung disease in patients presenting with dyspnea. J Am Coll Cardiol 2002; 39: 202-9.

11. Shuthers AD. Introducing a new role for BNP: as a general indicator of cardiac structural disease rather than a specific indicator of systolic dysfunction only. Heart 2002; 87: 97-8.

12. Pereira-BarrettoAC, Ramires JAF. Insuficiência cardíaca: um problema de Saúde Publica. Rev Bras Cardiol 2000; 2: 142-7.

13. Giles T. The cost-effective way forward for the management of the patient with heart failure. Cardiology 1996; 87(suppl 1): 33-9.

14. DATASUS - Ministério da Saúde - http//www.datasus.gov.Br

15. Arnold JMO, Yusuf S, Young J, et al. Prevention of heart failure in the Heart Outcomes Prevention Evaluation (HOPE) study. Circulation 2003; 107: 1284-90.

16. The CAPRICORN investigators. Effect of carvedilol on outcome after myocardial infarction in patients with left ventricular dysfunction: the CAPRICORN randomized trial. Lancet 2001; 357: 1385-90.

17. Starr I, Luchi RJ. Blind study on the action of digitoxin on elderly women. Am Heart J 1969; 78: 740-51.

18. Johnson GD, McDevitt DG. Is maintenance digoxin necessary in patients with sinus rhythm? Lancet 1979; 1: 567-70.

19. The Captopril-Digoxin Multicenter Research Group. Comparative effects of therapy with captopril and digoxin in patients with mild to moderate heart failure. JAMA 1988; 259: 539-44.

20. Packer M, Gheorguiade M, Young JB, et al. Withdrawal of digoxin from patients with chronic heart failure treated with angiotensin converting-enzyme inhibitors. N Engl J Med 1993; 329: 1-7.

21. Uretsky BF, Young JB, Shahidi, et al. Randomized study assessing the effect of digoxin withdrawal in patients with mild to moderate chronic congestive heart failure: results of the PROVED trial. J Am Coll Cardiol 1993; 22: 955-62.

22. The Digitalis Investigation Group. The effect of digoxin on mortality and morbidity in patients with heart failure. N Engl J Med 1997; 336: 525-33.

23. Oliveira JrMT, Pereira-BarrettoAC, Canesin MF, Terzi CB, Wasjbrot DB, Ramires JAF. Mortalidade hospitalar e preditores de óbito em pacientes com insuficiência cardíaca descompensada. Rev Soc Cardiol Estado de São Paulo 2000; 10: 38.

24. Canesin MF, Giorgi D, Oliveira Jr MT, et al. Ambulatory blood pressure monitoring of patients with heart failure: a new prognosis marker. Arq Bras Cardiol 2002; 78: 83-9.
25. Del Carlo CH, Pereira-Barretto AC, Cassaro-Stuntz C, Latorre RDO, Ramires JAF. Cardiac troponin T and left ventricular ejection for early risk stratification in decompensated heart failure. J Card Fail 2001; 7: 68.

26. The SOLVD Investigators. Effect of enalapril on mortality and the development of heart failure in asymptomatic patients with reduced left ventricular ejection fractions. N Engl J Med 1992; 327: 685-91.

27. The SOLVD Investigators. Effect of enalapril on survival in patients with reduced left ventricular ejection fractions and congestive heart failure. NEngl J Med 1991; 325: 293-302.

28. Coats AJS. Heart failure. What causes the symptoms of heart failure? Heart 2001; 86: 574-78.

29. Pfeffer MA, Braunwald E, Moye LA, et al. Effect of captopril on mortality and morbidity in patients with left ventricular dysfunction after myocardial infarction: results of the Survival and Ventricular Enlargement Trial. N Engl J Med 1992; 327: 669-77.

30. Mason S, Vago T, Baldi G etal. Comparative measurement of N-terminal Pro-brain natriuretic peptide in ambulatory patients with heart failure. Clin Chem Lab Med 2002; 40: 761-63.

31. Troughton RW, Frampton CM, Yandle TG, et al. Treatment of heart failure guided by plasma aminoterminal brain natriuretic peptide (N-BNP) concentrations. Lancet 2000; 355: 1126-30.

32. Omland T, Persson A, Ng L, et al. N-terminal Pro-B type natriuretic peptide and long-term mortality in acute coronary syndromes. Circulation 2002; 106: 2913-18.

33. Richards AM, Nicholls G, Yandle TG, et al. Plasma N-terminal Pro-brain natriuretic peptide and adrenomedullin: new neuro-hormonal predictors of left ventricular function and prognosis after myocardial infarction. Circulation 1998; 97: 1921-9.

34. Zugck C, Haunstetter A, Kruger C, et al. Impact of beta-blocker treatment on the prognosis value of currently used risk predictors in congestive heart failure. J Am Coll Cardiol 2002; 39: 1615-22.

35. Packer M, Fowler MB, Roecker EB, et al. Effect of carvedilol on the morbidity of patients with severe chronic heart failure: results of the carvedilol prospective randomized cumulative survival (COPERNICUS) study. Circulation 2002; 106: 2194-9.

36. Pitt B, Zannad F, Remme WJ, et al. The effect of spironolactone on morbidity and mortality in patients with severe heart failure. N Engl J Med 1999; 341: 709-17. 